Esta revista forma parte del acervo de la Biblioteca Jurídica Virtual del Instituto de Investigaciones Jurídicas de la UNAM http://www.juridicas.unam.mx/ https://biblio.juridicas.unam.mx/bjv

https://revistas.juridicas.unam.mx/

DOI: http://dx.doi.org/10.22201/iij.24487899e.2021.33.16331

INFORME DE SEGURIDAD SOCIAL

Universidad Nacional Autónoma de México, IIJ-BJV, 2021 https://revistas.juridicas.unam.mx/index.php/derecho-social/issue/archive 


\title{
INFORME: AVANCES Y RETROCESOS DE LA SEGURIDAD SOCIAL EN MÉXICO, 2020*
}

\author{
REPORT: PROGRESS AND SETBACKS \\ OF SOCIAL SECURITY IN MEXICO, 2020
}

RAPPORT: PROGRES ET RECULS

DE LA SÉCURITÉ SOCIALE DU MEXIQUE, 2020

\section{Gabriela MENDIZÁBAL BERMÚDEZ ${ }^{* *}$}

\begin{abstract}
RESUMEN: La seguridad social es un derecho humano que se encuentra en constante evolución. Esto es reconocible en cada país, a través de diversos sucesos, de los cuales sobresalen: el proceso legislativo, que genera nuevas normas jurídicas para asegurar que se garantizará el derecho humano a la seguridad social; las diferentes resoluciones que emite el Poder Judicial, con lo cual proporciona la interpretación de dichas normas jurídicas; de forma que inclusive se puede ampliar la cobertura prestacional y la política social que el gobierno promueve a través de programas sociales. En este contexto, la seguridad social puede presentar avances o retrocesos si se analiza en un periodo determinado. Por lo anterior, este informe se ocupa de presentar los eventos más importantes de 2020 en materia de seguridad social en México.
\end{abstract}

Palabras clave: derecho internacional de la seguridad social, México 2020, programas sociales, seguridad social.

ABSTRACT: Social security is a constantly evolving human right. One can see this in every country through various events, of which three stand out:

* Recibido el 11 de noviembre de 2020 y aceptado para su publicación el 15 de marzo de 2021.

* Profesora-investigadora titular C de la Facultad de Derecho y Ciencias Sociales de la Universidad Autónoma del Estado de Morelos en México; miembro del Sistema Nacional de Investigadores del Consejo Nacional de Ciencia y Tecnología de México; nivel II, y profesora de la Maestría en Derecho Laboral de la Universidad El Externado, Colombia; mgabriela@uaem.mx; ORCID ID: https:// orcid.org/0000-0003-3681-4025. 
the legislative process, which generates new legal norms to ensure the guarantee of the human right to social security; the different resolutions delivered by the judicial authority, which give a legal interpretation to the norms in such a way that it is even possible to expand the benefit coverage and the social policy that the government promotes through social programs. In this context, Social Security can present advances or setbacks if it is analyzed in a certain period. Due to this, the aim of this report is to present the most important events of 2020 in terms of social security in Mexico.

Keywords: international social security law, Mexico 2020, social programs, social security.

RÉSUMÉ: La sécurité sociale est un droit de l'homme en constante évolution. C'est reconnu dans chaque pays à travers de divers événements, dans lequel se démarquent: le processus législatif, qui génère de nouvelles normes juridiques pour garantir le droit humain à la sécurité sociale; les différentes résolutions émises par le pouvoir judiciaire, lesquelles donnent une interprétation aux normes juridiques, de telle sorte que la couverture des prestations et la politique sociale que le gouvernement promeut par le biais de programmes sociaux puissent être étendues. Dans ce contexte, la sécurité sociale peut présenter des avancées ou des reculs si elle est analysée dans un certain laps de temps. C'est pourquoi ce rapport est destiné à démontrer une présentation des événements les plus importants de laannée 2020 en matière de sécurité sociale au Mexique.

Mots-clés: droit international de la sécurité sociale, Mexique 2020, programmes sociaux, sécurité sociale.

SUMARIO: I. Introducción. II. Contexto socioeconómico y politico. III. Los cambios en programas y politicas sociales. IV. Principales resoluciones de la Suprema Corte de Justicia de la Nación. V. Reformas legislativas. VI. Seguridad social internacional.

VII. Conclusiones. VIII. Fuentes de investigación.

\section{INTRODUCCIÓN}

$O$ in duda 2020 estuvo marcado en el mundo por los efectos de la pandemia ocasionada por el virus SARS-CoV-2. El derecho social no estuvo ausente a esos resultados, y en el caso mexicano, de un lado, desafortunada- 
mente es reconocible la falta de liderazgo que condujo a una casi inexistente política laboral y de seguridad social en beneficio de los trabajadores y sus familiares, pero también la falta de apoyo a los empleadores. De otro lado, el gobierno mexicano impulsó cambios en materia sanitaria para materializar una cobertura universal en caso de infección por el virus. Esto para México es un gran reto, en virtud de que se cuenta con una población asegurada de 81.3 millones de personas, ${ }^{1}$ mientras que 48.8 millones reciben únicamente prestaciones sanitarias de la asistencia social. ${ }^{2}$ Pese a ello, al cierre de 2020 el país perdió 128771 habitantes por la COVID-19 y su tasa de contagios es de 1186 por cada cien mil habitantes. ${ }^{3}$

Fuera del tema de la pandemia, vale la pena reflexionar sobre diversos sucesos importantes en torno a la seguridad social.

Es en este sentido, que el informe intenta dar una respuesta a la hipótesis sobre la seguridad social en México, la cual presenta año con año avances en algunas áreas y retrocesos en otras. Por lo mismo, el análisis se compone de cinco apartados: el primero se dedica a reflejar brevemente el contexto socioeconómico y político de México, por ello reúne algunos datos estadísticos para contextualizar la problemática en materia de seguridad social; el segundo apartado trata de los cambios en programas y políticas sociales, para dar cuenta de las medidas del gobierno en torno a la asistencia social; los apartados cuarto y quinto se ocupan de reseñar algunas de las resoluciones de la Suprema Corte de Justicia de la Nación, así como de las reformas legislativas que sobresalieron en este año respectivamente; el apartado sexto analiza el avance en materia de seguridad social desde el aspecto internacional. El informe ciera con las conclusiones pertinentes y las fuentes de investigación.

\section{CONTEXTO SOCIOECONÓMICO Y POLÍTICO}

El aspecto económico en el país para 2020 resultó ser un tema negativo, principalmente por las consecuencias que ha traído la pandemia generada por la COVID-19 en todo el mundo. El Fondo Monetario Internacional (FMI)

1 Segundo Informe de Gobierno 2020, Presidencia de la República, México, Gobierno de México, 2020, p. 241; disponible en https://presidente.gob.mx/mp-content/uploads/2020/09/PRESI DENTE\%20AMLO\%202INFORME\%20DE\%20GOBIERNO\%202019-2020.pdf, consultado el 7 de enero de 2021.

2 Ibidem, p. 242.

3 COVID-19 México, México, Gobierno de México, 2021; disponible en https://datos.co vid-19.conacyt.mx/, consultado el 7 de enero de 2021. 
calculó que el producto interno bruto (PIB) por habitante en México cayó $9.9 \%$ en $2020 ;{ }^{4}$ asimismo, estableció que el valor generado por las actividades económicas en México no compensará el crecimiento de la población. Por su parte, la Conferencia de Naciones Unidas sobre Comercio y Desarrollo, en su reporte "Comercio y Desarrollo 2020" proyectó que México tendría el peor desempeño del PIB pues registraría una caída del $10 \%$ en $2020 .{ }^{5}$

A pesar de ello, se debe resaltar que el primer ingreso de la economía mexicana proviene de las remesas que ingresan al país, en su mayoría por trabajadores migrantes en Estados Unidos de América y Canadá. Para 2020 las remesas alcanzaron un nuevo récord, generando un ingreso de $860 \mathrm{mil}$ millones de pesos (39,50 billón USD), lo cual representó un incremento de $8.4 \%$ más que en $2019 .{ }^{6}$ De lo anterior, persiste el crecimiento de las remesas que ingresan a México en los últimos cinco años, conforme a la siguiente tabla:

Remesas ingresadas a México en los últimos cinco años

\begin{tabular}{|c|c|}
\hline Año & Cantidad \\
\hline 2020 & 39,50 billón USD \\
\hline 2019 & 35,46 billón USD \\
\hline 2018 & 33,48 billón USD \\
\hline 2017 & 28,60 billón USD \\
\hline 2016 & 26.97 billón USD \\
\hline
\end{tabular}

FUENTE: Elaboración propia a partir de los anuarios de Migración y remesas México de los años 2016, 2017, 2018, 2019 y 2020 realizadas por BBVA Research.

$\mathrm{Al}$ respecto, la Organización Internacional para las Migraciones señaló en su "Informe sobre las migraciones en el mundo 2020" que México se encuen-

4 Cfr. Informes de perspectivas de la economía mundial octubre de 2020, FMI, Estados Unidos de América, 2020; disponible en https:// wwm.imf.org/es/Publications/WEO/Issues/2020/09/30/ world-economic-outlook-october-2020, consultado el 5 de enero de 2021.

5 Cfr. Informe sobre el comercio y el desarrollo 2020 de la pandemia mundial a la prosperidad para todos: evitar otra década perdida, ONU, Suiza, 2020; disponible en https://mmw.onu.org.mx/presentacion-del -informe-2020-sobre-comercio-y-desarrollo-de-la-unctad/, consultado el 4 de enero de 2021.

6 Cfr. BBVA México: En 2020, las remesas alcanzarán los 39,500 millones de dólares pese a la pandemia, México, BBVA, 2020; disponible en https://www.bbva.com/es/mx/bbva-mexico-estimaque-en-2020-las-remesas-alcanzaran-los-39500-mdd-8-4-pese-a-la-pandemia/, consultado el 4 de enero de 2021. 
tra dentro de los primeros tres países en el mundo que recibieron más remesas internacionales desde los Estados Unidos de América. ${ }^{7}$

En materia de empleo, durante 2020 las estadísticas laborales en México no son alentadoras en gran medida por la COVID-19 y sus repercusiones en la materia. Datos proporcionados por el Banco de México (BANXICO) refieren que se perdieron 10 millones de empleos informales y dos millones de trabajos formales debido a la crisis originada por la pandemia. ${ }^{8}$

El Instituto Nacional de Estadística y Geografía (INEGI), en su última Encuesta Nacional de Ocupación y Empleo del tercer trimestre de 2020, menciona que la población económicamente activa (PEA) para ese periodo en el país fue de 53.8 millones de personas, lo que refleja 3.6 millones menos en comparación al mismo periodo de 2019. La población ocupada representó el 94.9\% respecto de la PEA, es decir, las personas que trabajaron en la semana anterior a la entrevista o que no trabajaron, pero mantenían un vínculo laboral con la unidad económica para la que trabajan; ${ }^{9}$ en tanto la población desocupada de la PEA fue de 2.7 millones de personas. ${ }^{10} \mathrm{La}$ división de la población activa por sexo se conformó de 33.5 millones de hombres frente a 20.3 millones de mujeres.

Respecto a la población ocupada informal para este periodo fue de 27.7 millones de personas, lo que significa que más del $60 \%$ de la población ocupada se encuentra en la economía informal. ${ }^{11}$

En relación a la pobreza, el Consejo Nacional de Evaluación de la Política de Desarrollo Social (CONEVAL), como organismo público descentralizado de la administración pública federal encargado de generar información objetiva sobre la situación de la política social y la pobreza en México, ${ }^{12}$ informó en su última medición de la pobreza 2018 que en México 61.1 mi-

7 India, China y en tercer lugar México. Véase Informe sobre las Migraciones en el Mundo 2020, Suiza, OIM-ONU Migración, 2020, p. 12; disponible en bttps://publications.iom.int/system/files/ pdf/wmr_2020_es.pdf, consultado el 6 de enero de 2021.

8 Cambios estructurales en el mercado laboral, Banco de México, 2020; disponible en bttps:/ / www.banxico.org. mx/publicaciones-y-prensa/presentaciones/\%7B03A31AC2-D1CD-C0CA-955BB8AEFE71 AFAB\%7D.pdf, consultado el 4 de enero de 2021.

9 Resultados de la encuesta nacional de ocupación y empleo. nueva edición (ENOEN) cifras durante el tercer trimestre de 2020, México, INEGI, 2020; disponible en https:/ / www.inegi.org.mx/ contenidos/ programas/enoe/15ymas/doc/enoe_n_nota_tecnica_trim3.pdf, consultado el 4 de enero de 2021.

10 Idem.

11 Idem.

12 ¿Quiénes somos?, México, Coneval, 2020; disponible en https://mww.coneval.org.mx/quie nessomos/Paginas/Quienes-Somos.aspx, consultado el 4 de enero de 2021. 
llones de mexicanos se encontraba en situación de pobreza y 21 millones en condición de pobreza extrema. ${ }^{13}$ Asimismo, estableció que para la medición de la pobreza se utilizan líneas de ingreso, cuyos datos hasta diciembre de 2020 se exponen a continuación.

Línea de pobreza extrema por ingresos, que equivale al valor de la canasta alimentaria por persona de 1206.24 pesos $(60.13 \text { USD) })^{14}$ en la zona rural y 1676.11 pesos (83.55 USD) en la zona urbana; ${ }^{15}$ y la línea de pobreza por ingresos, que equivale al valor total de la canasta alimentaria y de la canasta no alimentaria por persona al mes, la cual fue de 2153.82 pesos (107.36 USD) en la zona rural y 3295.73 pesos (164.29 USD) en la zona urbana. ${ }^{16}$

$\mathrm{Al}$ respecto, se debe señalar que el salario mínimo nacional tuvo un incremento del 15\% y se fijó en 141.70 pesos (7.06 USD) diarios, es decir 4251 pesos (211.91 USD) mensual para 2021. ${ }^{17}$

Por su parte, la CEPAL en su informe especial COVID-19 núm. 5 de la CEPAL. Enfrentar los efectos cada vez mayores del COVID-19 para lograr una reactivación con igualdad: nuevas proyecciones, ha pronosticado que a raíz de la crisis económica generada por la pandemia, está dejará millones de personas en situación de pobreza, y México será uno de los países de América Latina con mayor tasa de aumento de pobreza. Refiere que actualmente México es el tercer país en América Latina que reporta un mayor crecimiento en población pobre, el porcentaje de mexicanos en situación de pobreza pasará de $41.9 \%$ en 2019 a $49.5 \%$ para el 2020 , mientras que la pobreza extrema de $11.1 \%$ a $17.4 \% .^{18}$

13 Cfr. Medición de la pobreza, Coneval, México, 2020; disponible en bttps:/ / wmm.coneval.org. $m x /$ Medicion/Paginas/PobrezaInicio.aspx, consultado el 5 de enero de 2021.

14 El tipo de cambio para este informe es 20.06 pesos mexicanos $=1 \mathrm{USD}$, datos del Banco de México del 11 de enero de 2021. Véase Banco de México, Tipo de cambio, México, Banco de México, 2021; disponible en https://www.banxico.org.mx/tipcamb/main. do?page =tiperidioma $=$ sp, consultado el 7 de enero de 2021 .

15 Evolución de las líneas de pobreza por ingresos, México, Coneval, 2020; disponible en https:/ / wnw.coneval.org.mx/Medicion/MP/Paginas/Lineas-de-bienestar-y-canasta-basica.aspx, consultado el 4 de enero de 2021.

16 Idem.

17 "Acuerda Conasami incremento del salario mínimo del 15\% para 2021", Comisión Nacional de Salarios Mínimos, México, Gobierno de México, 2020; disponible en https:/ / wmm. gob.mx/conasami/prensa/acuerda-conasami-incremento-del-salario-minimo-del-15-para-2021-259690, consultado el 11 de enero de 2021.

18 Comisión Económica para América Latina y el Caribe, Enfrentar los efectos cada vez mayores del COVID-19 para una reactivación con igualdad: nuevas proyecciones, 2020, p. 5; disponible en https:/ / repositorio.cepal.org/ bitstream/ handle/11362/45782/4/S2000471_es.pdf, consultado el 4 de enero de 2021). Cabe aclarar que los datos reportados de pobreza para México por la CEPAL 
En relación con las medidas de política social para preservar el trabajo, la seguridad social y la protección social de los trabajadores por la pandemia, hemos sido testigos desde el inicio de la pandemia de cómo el gobierno de cada país ha dictado diversas medidas sanitarias, laborales y económicas. Algunas se han elevado a normas jurídicas por los poderes legislativos, otras sólo son medidas administrativas; sin embargo, la mayoría solo sirven para atender y superar la crisis, pero las consecuencias de la pandemia han pasado de ser sólo una crisis y están conformando una nueva realidad que requiere medidas para atender los efectos en el trabajo y la economía que la pandemia está ocasionando a mediano y largo plazo.

En ese contexto, en México resaltan las siguientes medidas:

a) En materia laboral

- Denominación de emergencia sanitaria. El 30 de marzo del $2020^{19}$ se publicó el acuerdo emitido por el Consejo de Salubridad General, que declaró emergencia sanitaria por causa de fuerza mayor a la epidemia de enfermedad generada por el virus SARS-CoV-2 (COVID-19), lo que suscitó una incertidumbre jurídica en materia laboral. Lo anterior, debido a que la Ley Federal del Trabajo, en sus artículos 42 bis, 427 fracción VII y 429 fracción $I V, 20$ en materia de suspensión de las relaciones de trabajo, no contempla el supuesto de emergencia sanitaria, sino una declaratoria de contingencia sanitaria, lo cual tiene consecuencias jurídicas distintas.

Esto tuvo como efecto negativo que los empleadores hasta el momento no hayan podido aplicar la suspensión jurídica de las relaciones laborales de sus trabajadores, lo que ocasionó que se aumentaran los despidos y otras medidas irregulares (vacaciones sin pago, reducción de salarios, etc.).

- Teletrabajo. El 1 de abril de 2020 la Secretaría de Trabajo y Previsión Social expidió una "Guía para implementar el teletrabajo en los centros

son menores que los nacionales determinados por Coneval y esto se debe al instrumento que se aplica para la medición de la pobreza.

19 Acuerdo por el que se declara emergencia sanitaria por causa de fuerza mayor, a la epidemia de enfermedad generada por el virus SARS-CoV-2 (COVID-19), Diario Oficial de la Federación, México, 2020; disponible en https:// wmw.dof.gob.mx/nota_detalle.php? codigo $=5590745$ \& fecha $=30 / 03 / 202$ 0\#: : :text=Primero--,Se\%20declara\%20 como\%20emergencia\%20sanitaria\%20por $\% 20$ causa $\% 20 \mathrm{de} \% 20$ fuerza\%20mayor,prevista\%20en\%20el\%20numeral\%20anterior, consultado el 7 de enero de 2021 .

20 Ley Federal del Trabajo. 
de trabajo en el marco de las acciones para enfrentar el COVID-19", ${ }^{21}$ únicamente de carácter informativo, en la cual se establecen una serie de recomendaciones tanto para el empleador como para las y los trabajadores que implementen la modalidad de teletrabajo en sus centros laborales, con la intención de acompañarlos durante esta transición respetando los derechos y obligaciones de ambas partes.

b) En materia de seguridad social

- Atención sanitaria. El 13 de abril de 2020 se firmó el convenio "Todos juntos contra el COVID-19" entre el Gobierno de México y la Asociación Nacional de Hospitales Privados y el Consorcio Mexicano de Hospitales, para que los derechohabientes del sistema de salud pública recibieran atención médica y hospitalaria que no guarde relación con la COVID-19 en hospitales privados. Esta medida tuvo como finalidad que los institutos públicos de salud den prioridad a la atención de pacientes con COVID-19 y evitar que se saturen..$^{22}$

- COVID-19 como riesgo de trabajo. El 29 de julio de 2020 se publicó en el Diario Oficial de la Federación el acuerdo del H. Consejo Técnico del Instituto Mexicano del Seguro Social acerca del reconocimiento de la enfermedad COVID-19 como riesgo de trabajo para las y los trabajadores durante el periodo de la contingencia. Este acuerdo da la posibilidad a los trabajadores que sean diagnosticados con COVID-19, en el desarrollo de actividades prioritarias, para que puedan tramitar su incapacidad temporal ante el IMSS, que les permita justificar las inasistencias en el trabajo durante el tiempo de recuperación, así como garantizar las prestaciones económicas y en especie, para él y sus beneficiarios, como riesgo de trabajo y no sólo como enfermedad general. ${ }^{23}$

21 Guía para implementar el teletrabajo en los centros de trabajo en el marco de las acciones para enfrentar el COVID-19, México, Secretaría de Trabajo y Previsión Social, 2020; disponible en bttps:// www.gob.mx/cms/uploads/attachment/file/543661/INTRODUCCIO_N.pdf, consultado el 7 de enero de 2021.

22 Convenio con hospitales privados ;Todos juntos contra el COV ID-19!, México, Gobierno de México, 2020; disponible en bttps:// wmw.gob.mx/issste/es/articulos/convenio-con-hospitales-privados?idiom=es, consultado el 7 de enero de 2021.

23 Acuerdo ACDO.AS2.HCT.240620/173.P.DPES, dictado por el H. Consejo Técnico en sesión ordinaria el día 24 de junio de 2020, por el que se autorizan estrategias para prorrogar las prestaciones en especie y/o en dinero a los asegurados con incapacidad temporal para el trabajo que lleguen a término de ley y a los beneficiarios hijos incapacitados que cumplen 16 años, así como reconocimiento de la enfermedad COVID-19 
- Prestaciones de seguridad social sustitutas del seguro de desempleo. El Instituto Mexicano del Seguro Social informó en julio que las personas que perdieron su empleo durante la emergencia sanitaria podían tramitar el retiro parcial por desempleo. Este retiro es un trámite mediante el cual el trabajador puede hacer un retiro parcial de su cuenta individual por situación de desempleo que, según la modalidad que aplique, puede ser equivalente a:

- Modalidad A: 30 días de su último salario base de cotización con un límite de 10 unidades de medida de actualización (2641.15 pesos mexicanos para 2020).

Modalidad B: lo que resulte menor entre 90 días del salario base de cotización del trabajador en las últimas 250 semanas o las que tuviere y el $11.5 \%$ de los recursos acumulados en la subcuenta de retiro, cesantía en edad avanzada y vejez (RCV). ${ }^{24}$

De la misma forma desde el 15 de abril, el Instituto del Fondo Nacional de la Vivienda para los Trabajadores (Infonavit) inició el proceso para el registro y entrega del seguro de desempleo que otorga a sus acreditados activos y que han perdido su relación laboral a causa de la contingencia de la COVID-19. Esta prestación consiste en cubrir el pago de las mensualidades por la adquisición de una vivienda en un $100 \%$ durante 12 quincenas, es decir, seis meses.

- Programas sociales. Como una medida para hacer frente a las afectaciones económicas de la población en México, el presidente Andrés Manuel López Obrador decretó que los beneficiarios de los programas para el Bienestar de las Personas Adultas Mayores, programa social que otorga una pensión a personas de 65 años o más en México, así como del programa Becas Benito Juárez, ${ }^{25}$ que otorga becas a estudiantes de educación básica, media superior y superior recibieran un anticipo de la

como riesgo de trabajo en trabajadores IMSS, durante el periodo de contingencia, Diario Oficial de la Federación, México, Secretaría de Gobernación, 2020; disponible en https:// mmm.dof.gob.mx/nota_detalle.php?c odigo $=5597452$ éfecha $=29 / 07 / 2020$, consultado el 7 de enero de 2021.

24 Personas que perdieron su empleo durante emergencia sanitaria pueden tramitar Retiro Parcial por Desempleo: IMSS, México, IMSS, 2020; disponible en http://www.imss.gob.mx/prensa/archivo/ 202006/368, consultado el 7 de enero de 2021.

25 Becas para el Bienestar Benito Juárez. Conferencias sobre Programas del Bienestar, México, Gobierno de México, Secretaría de Trabajo y Previsión Social, 2020; disponible en https:/ / www. gob.mx/stps/articulos/becas-para-el-bienestar-benito-juarez-conferencias-bienestar, consultado el 11 de enero de 2021). 
pensión así como de las becas, correspondientes a dos meses. ${ }^{26}$ Estos adelantos se repitieron en dos ocasiones durante 2020.

\section{LOS CAMBIOS EN PROGRAMAS Y POLÍTICAS SOCIALES}

Los acontecimientos más importantes durante 2020 en este tema pueden catalogarse de la siguiente manera.

\section{Creación del Programa de Saludy Bienestar Comunitario}

De acuerdo con lo dispuesto por el artículo 29 y el anexo 25, del Presupuesto de Egresos de la Federación para el Ejercicio Fiscal 2020, ${ }^{27}$ se crea el Programa de Salud y Bienestar Comunitario que, de acuerdo con sus reglas de operación, ${ }^{28}$ tiene el propósito de fortalecer la salud y bienestar comunitario de las personas de localidades de alta y muy alta marginación, a través de la práctica de estilos de vida saludables, por lo que se privilegia un abordaje colectivo, desde un enfoque de promoción de la salud y determinantes sociales, entendida ésta como un derecho que trasciende el cuidado personal del equilibrio biológico, para abarcar el derecho a participar organizadamente en la modificación y mejoramiento de las circunstancias de carácter social que limitan el desarrollo integral de los individuos y comunidades. Esto es, aspirar a vivir en un entorno donde se cultiven estilos de vida saludables, definidos como el desarrollo de capacidades individuales y colectivas.

Este programa financia proyectos que cumplan con los requisitos planteados y sean aprobados conforme a las reglas de operación con un apoyo económico de hasta 600000.00 pesos (29,910 USD) con el propósito de for-

26 Adultos mayores recibirán bimestre adelantado de pensión, anuncia presidente; programas sociales se fortalecerán ante COVID-19, México, Gobierno de México, 2020; disponible en https://presidente.gob.mx/adultos-mayores-recibiran-bimestre-adelantado-de-pension-anuncia-presidenteprogramas-sociales-se-fortaleceran-ante-covid-19/, consultado el 7 de enero de 2021.

27 Presupuesto de Egresos de la Federación para el ejercicio Fiscal 2020, Diario Oficial de la Federación, México, Cámara de Diputados del H. Congreso de la Unión; disponible en http:/ / www.diputados.gob.mx/LeyesBiblio/abro/pef_2020/PEF_2020_abro.pdf, consultado el 21 de enero de 2021.

28 Acuerdo por el que se emiten las Reglas de Operación del Programa de Salud y Bienestar Comunitario, para el Ejercicio Fiscal 2020, Diario Oficial de la Federación, México; disponible en https:/ / wwn.dof.gob.mx/ nota_detalle.php?codigo $=5583027$ \&fecha $=28 / 12 / 2019$, consultado el 7 de enero de 2021. 
talecer uno o más componentes de la salud y el bienestar comunitario, el cual puede incluir capacitaciones, proyectos sociales o productivos, así como otros insumos y acciones requeridas para el logro de los objetivos planteados por el programa. En caso de que la propuesta exceda el costo máximo señalado, se podrá hacer una excepción siempre y cuando la justificación lo amerite.

\section{Programa Bienestar de las Personas en Situación de Emergencia Social y Natural}

Se trata de un cambio de denominación del antiguo programa de asistencia social: Bienestar de las Personas en Emergencia Social o Natural, para nombrarse ahora como Bienestar de las Personas en Situación de Emergencia Social y Natural. ${ }^{29}$ Este programa tiene como objetivo atender las necesidades de las personas, prioritariamente de niñas, niños, adolescentes, personas adultas mayores, personas con discapacidad, personas indígenas y afromexicanas, en poblaciones afectadas por fenómenos sociales y naturales a través de la entrega de apoyos económicos o en especie en el lugar donde se suscite la emergencia social o natural, con el fin de reducir el impacto negativo en la esfera de sus derechos sociales. Los beneficios económicos se otorgan a través de tarjetas bancarias y/o cheques o por los medios que determine la Secretaría de Bienestar, y son equivalente a una Unidad de Medida y Actualización (UMA) mensual, que para 2021 es de 2 724.45 pesos (135.81 USD)..$^{30}$

\section{Programas de asistencia social eliminados}

Por último, se destaca que en el ejercicio 2020 se eliminaron algunos programas de relevancia, como lo son el Programa 3 x 1 para Migrantes y el Programa de Coinversión Social. ${ }^{31}$

29 Acuerdo por el que se emiten los Lineamientos de Operación del Programa para el Bienestar de las Personas en Emergencia Social o Natural para el Ejercicio Fiscal 2020, Diario Oficial de la Federación, México, 2020; disponible en https://wnm.gob.mx/cms/uploads/attachment/ file/578546/Lineamientos_Emergencia_Social.pdf, consultado el 7 de enero de 2021.

30 UMA, México, INEGI, 2021; disponible en https:// www.inegi.org.mx/temas/uma/, consultado el 7 de enero de 2021.

31 Inventario Coneval de Programas y Acciones Federales de Desarrollo Social 2019-2020. Presentación y Análisis. México, Coneval, 2020, p. 35; disponible en https://mmw.coneval.org.mx/evaluacion/ipfe/ Paginas/default.aspx, consultado el 7 de enero de 2021. 
El Programa 3x1 para Migrantes era un programa del Gobierno de la República que comenzó a cargo de antigua Secretaría de Desarrollo Social, hoy Secretaría de Bienestar, y apoyaba las iniciativas de los migrantes para realizar proyectos de infraestructura social o servicios comunitarios, así como proyectos productivos comunitarios, familiares o individuales que contribuían al desarrollo de sus comunidades de origen, mediante la aportación de los gobiernos federal, estatal y municipal, así como de los clubes u organizaciones de migrantes radicados en el extranjero. ${ }^{32}$

El Programa de Coinversión Social era un programa destinado a fortalecer a los actores sociales a través de la promoción de proyectos de coinversión entre el gobierno y éstos, para apoyar a la población en situación de pobreza, exclusión, marginación, discapacidad, desigualdad por género o vulnerabilidad. ${ }^{33}$

\section{PRINCIPALES RESOLUCIONES \\ DE La Suprema CorTe de Justicia de la NACiÓN}

La Suprema Corte de Justicia de la Nación (SCJN) ha emitido criterios importantes en materia de seguridad social, los cuales se ven reflejados en las siguientes jurisprudencias y tesis aisladas.

\section{Derechos pensionarios extranjeros}

A causa de diversas demandas interpuestas por trabajadores extranjeros ${ }^{34}$ para que se les haga la devolución de las aportaciones de su cuenta individual de la Afore argumentado que regresan a su país de origen, en noviembre de 2020 la SCJN 35 estableció jurisprudencia en relación a que los trabajadores

32 Programa $3 \times 1$ para Migrantes, México, Secretaría de Desarrollo Social; disponible en http:// www.sedesol.gob.mx/work/models/SEDESOL/Transparencia/TransparenciaFocalizada/Programas_Sociales/pdf/3x1_para_migrantes.pdf, consultado el 7 de enero de 2021).

33 Programa de Coinversión Social, México, Secretaría de Desarrollo Social; disponible en http:// www.sedesol.gob.mx/work/models/SEDESOL/Transparencia/TransparenciaFocalizada/Programas_Sociales/pdf/coinversion_social.pdf, consultado el 7 de enero de 2021.

34 Algunas demandas similares presentadas en el Séptimo Tribunal Colegiado en Materia de Trabajo del Primer Circuito, al resolver el amparo directo DT.-1124/2015, y el sustentado por el Décimo Segundo Tribunal Colegiado en Materia de Trabajo del Primer Circuito, al resolver el amparo directo DT.-668/2019.

35 Tesis PC.I.L. J/67 L (10a.), Gaceta de Seminario Judicial de la Federación, décima época, noviembre 2020, t. II, p. 1813, TRABAJADORES EXTRANJEROS. TIENEN DERECHO A LA DEVO- 
extranjeros tienen derecho a que se les haga la devolución de los recursos acumulados en su cuenta individual abonadas en su Afore, así como las aportaciones realizadas en la subcuenta de vivienda, cuando el trabajador extranjero regrese de manera definitiva a su país de origen, por lo que no es necesario que éstos cumplan los requisitos generales establecidos en la ley para efectos de su devolución, como tener 60 o más años de edad así como tener las semanas cotizadas solicitadas por la Ley del Seguro Social.

La SCJN refiere que en las leyes aplicables en la materia prevalece el principio de igualdad entre trabajadores nacionales y extranjeros, sin embargo, tratándose de trabajadores extranjeros procede hacer un trato diferenciado para alcanzar una igualdad sustantiva, debido a que el trabajador extranjero ha laborado en nuestro país y tiene parte de su patrimonio en los recursos acumulados en su cuenta individual de Afore, y para efectos de entablar una igualdad sustantiva es necesario eliminar las condiciones de desventaja que afectan a los extranjeros en los casos en que regresen a residir a su país de origen de forma definitiva, ya que al no poder cumplir con los requisitos contemplados en la leyes correspondientes, no podrán tener acceso a la devolución de sus aportaciones y para efectos de garantizar una igualdad de hecho y no de derecho, los trabajadores extranjeros no deben tener el mismo trato que los nacionales, pues con ello se les genera un obstáculo que les impide gozar de manera real y efectiva los recursos de sus cuentas individuales, caso contrario con los trabajadores mexicanos, quienes al residir en este país sí tendrán la oportunidad de continuar cotizando y eventualmente acceder a esos recursos con base en los requisitos que exijan las leyes de la materia. ${ }^{36}$

\section{El incremento de las pensiones otorgadas al amparo} de la Ley del Seguro Social derogada debe efectuarse en febrero

La SCJN emitió jurisprudencia ${ }^{37}$ a raíz de una contradicción de criterios entre tribunales federales sobre el incremento de las pensiones otorgadas por la Ley del Seguro Social derogada (Ley del Seguro Social de 1973).

LUCIÓN DE LOS RECURSOS ACUMULADOS EN SU CUENTA INDIVIDUAL DEPOSITADA EN LA ADMINISTRADORA DE FONDOS PARA EL RETIRO (AFORE), ASÍ COMO DE LAS APORTACIONES AL FONDO DE LA SUBCUENTA DE VIVIENDA, CUANDO VUELVAN EN FORMA DEFINITIVA A SU PAÍS DE ORIGEN, SIN QUE LES SEAN EXIGIBLES LOS REQUISITOS PREVISTOS EN LA LEY.

36 Idem.

37 Tesis PC.IV.L. J/21 L (10a.), Gaceta de Seminario Judicial de la Federación, décima época, diciembre, 2020, PENSIONES OTORGADAS AL AMPARO DE LA LEY DEL SEGURO SOCIAL DE- 
La jurisprudencia establece que las pensiones que fueron otorgadas bajo el amparo de Ley del Seguro Social de 1973, derogada en 1997, deben actualizarse anualmente en febrero (al igual que las otorgadas por la Ley del Seguro Social vigente), con base en el Índice Nacional de Precios al Consumidor (INPC) correspondiente al año calendario anterior, que comprende de enero a diciembre del año previo a aquél donde se aumenta la pensión. Dicho cálculo se debe realizar conforme a lo establecido en la Ley del Impuesto sobre la Renta.

\section{COVID-19 y salud}

Los tribunales colegiados emitieron una jurisprudencia por reiteración de criterios $^{38}$ en relación que el Estado, a través de las instituciones públicas que prestan atención a la salud, en calidad de empleadores tienen que garantizar las medidas necesarias y suficientes al personal de salud que presta sus servicios en hospitales y que se encuentren expuestos al contagio del virus SARS-CoV-2 para no poner en peligro sus vidas al momento de desarrollar su trabajo.

Esta jurisprudencia nace como resultado de que personas trabajadoras de la salud del IMSS interpusieron diversos juicios de amparo ${ }^{39}$ en su contra, por la negativa de proporcionar material médico suficiente y de calidad para desempeñar su trabajo y atender de manera segura a los pacientes que acudieran al centro hospitalario por padecer algún síntoma o estar contagiadas con el virus SARS-CoV-2, puesto que el instituto de salud no tenía los insumos necesarios para proteger a sus trabajadores de la exposición al virus.

\section{Aplicación del cuadro básico de medicamentos}

Los seguros sociales en México se ciñen actualmente a la normativa que establece un cuadro básico de medicamentos, a los cuales están sujetos los

ROGADA. Su INCREMENTO DEBE EFECTUARSE ANUALMENTE EN EL MES DE FEBRERO, CONFORME AL ÍNDICE NACIONAL DE PRECIOS AL CONSUMIDOR (INPC) CORRESPONDIENTE AL AÑO CALENDARIO ANTERIOR.

38 Tesis XVII.1o.P.A. J/31 K (10a.) Gaceta de Seminario Judicial de la Federación, décima época, Tribunales Colegiados de Circuito, octubre 2020, VIRUS SARS-COV2 (COVID-19). Al CONSTITUIR SU BROTE UNA EMERGENCIA DE SALUD PÚBLICA DE IMPORTANCIA INTERNACIONAL AMERITA EL ESTABLECIMIENTO DE MEDIDAS PREVENTIVAS URGENTES PARA LA PROTECCIÓN DEL PERSONAL QUE PRESTA SUS SERVICIOS EN LOS HOSPITALES PÚBLICOS Y ESTÁ EXPUESTO AL CONTAGIO.

39 Queja 79/2020, Queja 80/2020, Queja 82/2020, Queja 87/2020, Queja 107/2020, presentadas en el Primer Tribunal Colegiado en Materias Penal y Administrativa del Décimo Séptimo Circuito 
médicos para prescribir las medicinas para los tratamientos de los asegurados. En este año, se presentó de manera insólita una resolución de la Corte a un derechohabiente del Instituto Mexicano del Seguro Social (IMSS), que solicitó a través de juicio de amparo que se le suministrara gratuitamente un medicamento, que fue prescrito por un médico ajeno a ese organismo, y que además no se encontraba incluido en el Cuadro Básico y Catálogo de Insumos del Sector Salud regulados por la Ley General de Salud.

La Corte, a través de criterio jurisprudencial, ${ }^{40}$ estableció que la institución de seguridad social debe realizar una comparación de medicamentos que sí están incluidos en el Cuadro Básico o Compendio Nacional de Insumos para la Salud o en sus propios catálogos institucionales, y si la conclusión de ese análisis es que el medicamento solicitado es el mejor tratamiento para el paciente-quejoso, la institución debe otorgarlo de inmediato; en caso contrario, debe comunicar su resolución al paciente para que éste decida, con conocimiento previo del análisis realizado, sobre su tratamiento.

Esto abre la puerta para que mediante la acción judicial se certifique si los medicamentos solicitados por el derechohabiente a través de juicio de amparo son de mayor eficacia terapéutica, seguridad y eficiencia para el padecimiento del paciente y en su caso se amplíe el cuadro básico de medicamentos.

\section{Minimo vital}

En 2020, la Corte, a través de dos resoluciones que devienen de juicios de amparo, ${ }^{41}$ establece criterios que coadyuvan al fortalecimiento de la interpretación del derecho al mínimo vital.

40 Tesis 2a./J. 40/2020 (10a.), Gaceta de Seminario Judicial de la Federación, décima época, octubre, 2020, t. I, p. 974, SUSPENSIÓN PROVISIONAL. DEBE OTORGARSE PARA QUE LA INSTITUCIÓN RESPONSABLE, DE INMEDIATO, ANALICE Y CERTIFIQUE EL MEJOR MEDICAMENTO PARA EL PADECIMIENTO DEL QUEJOSO, EN COMPARACIÓN CON LOS MEDICAMENTOS PREVISTOS EN EL CUADRO BÁSICO O COMPENDIO NACIONAL DE INSUMOS PARA LA SALUD. A consecuencia de la contradicción de criterios distintos entre otros tribunales: Contradicción de tesis 517/2019. Entre las sustentadas por los Tribunales Colegiados Segundo en Materia Administrativa del Cuarto Circuito, Primero en Materias Civil y de Trabajo del Décimo Séptimo Circuito y Primero del Noveno Circuito, (actual Tribunal Colegiado en Materia de Trabajo del Noveno Circuito), 10 de junio de 2020.

41 Amparo en revisión 309/2019. Tercer Tribunal Colegiado del Décimo Quinto Circuito; Queja 225/2019. Segundo Tribunal Colegiado en Materias Penal y Administrativa del Décimo Octavo Circuito. 
La primera se refiere a la jurisprudencia ${ }^{42}$ originada por el juicio de amparo interpuesto por un pensionado del gobierno del Estado de Morelos, contra un acto de autoridad por parte del Congreso del Estados de Morelos, al emitir un decreto que abroga la concesión de pensión del pensionado sin garantizarle el derecho de audiencia establecido en la Constitución mexicana y violando su derecho al mínimo vital al quitarle la pensión.

La segunda se generó mediante una tesis aislada, emitida por los Tribunales Colegiados de Circuito, como resultado de la interposición de juicio de amparo de un grupo de jubilados, que demandaron al Instituto de Seguridad y Servicios Sociales de los Trabajadores del Gobierno y Municipios del Estado de Baja California la falta de pago de sus pensiones. ${ }^{43}$

Los principales argumentos en ambos casos, que refuerzan el derecho al mínimo vital, fueron que el hecho de no garantizar el pago de la pensión tanto de los jubilados, como del pensionado, viola el derecho al mínimo vital, ya que a través del ingreso económico que se percibe por concepto de pensión las personas pueden adquirir los bienes-servicios que les permita entablar ese mínimo vital establecido en la Constitución.

\section{REFORMAS LEGISLATIVAS}

En el año 2020 existieron algunas reformas legislativas importantes en materia de seguridad social que merecen su análisis. Dichas reformas se catalogan de la siguiente manera.

\section{Reformas de pensiones}

El 9 de diciembre del 2020 se aprobó el Proyecto de decreto por el que se reforman, adicionan y derogan 19 artículos de la Ley del Seguro Social, más transitorios, en un hecho casi histórico y un tanto controversial, debido a que

42 Tesis PC.XVIII.P.A. J/7 A (10a.), Gaceta de Seminario Judicial de la Federación, décima época, febrero, 2020, t. II, p. 1866, SuSPENSIÓN PROVISIONAL EN EL JUICIO DE AMPARO. PROCEDE CONCEDERLA CONTRA LOS EFECTOS DEL DECRETO EXPEDIDO POR EL CONGRESO DEL ESTADO DE MORELOS A TRAVÉS DEL CUAL ABROGA UN DIVERSO DECRETO PENSIONARIO.

43 Tesis XV.3o.9 A (10a.), Gaceta de Seminario Judicial de la Federación, décima época, Tribunales Colegiados de Circuito, febrero, 2020, t. III, p. 2361, PENSIÓn JUBILATORIA. LA OMISIÓN RECURRENTE DE PAGARLA OPORTUNAMENTE VIOLA LOS DERECHOS HUMANOS A LA DIGNIDAD, AL MÍNIMO VITAL Y A LA SEGURIDAD SOCIAL DE LOS JUBILADOS. 
en el mismo día fue aprobada por la Cámara de Diputados con 441 votos en pro, 13 en contra y 6 abstenciones, ${ }^{44}$ y por el senado con 95 votos en pro y ninguno en contra. ${ }^{45}$

Dentro de las reformas que entraron en vigor el 1o. de enero de 2021 se encuentran las siguientes.

\section{A. Cambio del monto y requisitos para la pensión garantizada}

El artículo 170 y el 4o. transitorio modifican los requisitos para acceder a la pensión garantizada ${ }^{46}$ por vejez, cesantía en edad avanzada y retiro, pasando de 1250 a 750 semanas de cotización como mínimo; aumentando hasta llegar a 1000 semanas de cotización, conforme a la tabla prevista en este apartado normativo, además de tener 60 años o más de edad. El monto también cambia pasando de 3289.34 pesos $^{47}$ (163.97 USD) para todos los derechohabientes en el 2020 a establecer un parámetro de mínimos y máximos, teniendo como cuantía mínima de 2622.00 pesos (130.70 USD) y una máxima de 8241.00 pesos (410.81 USD) a partir del 2021. Para efectos del cálculo de las cuantías, se debe considerar el promedio del salario base de cotización, el número de semanas de cotización y la edad con que cuente el trabajador al momento de solicitar la pensión, con base en la tabla establecida en el artículo 170 de la Ley del Seguro Social.

Cabe aclarar que el monto de la pensión garantizada anteriormente se fijaba con base en el salario mínimo general, y la reforma contempla que se calculará con base en unidades de medida y actualización (UMA), que son "la referencia económica en pesos para determinar la cuantía del pago de las obligaciones y supuestos previstos en las leyes federales, de las entidades

44 Votaciones del primer periodo ordinario del tercer año de la LXIV Legislatura, Servicio de la Gaceta Parlamentaria, México, Cámara de Diputados, 2020; disponible en bttp://gaceta.di putados.gob.mx/Gaceta/Votaciones/64/vot64_a3primero.html, consultado el 10 de enero de 2021.

45 Gaceta del Senado, miércoles 09 de diciembre de 2020 Gaceta: LXIV/3PPO-72, México, Senado de la República, 2020; disponible en https://mmw.senado.gob.mx/64/gaceta_del_senado/2020 _12_09/2757\#418, consultado el 11 de enero de 2021.

46 Pensión garantizada es la que el Estado asegura a quienes cumplan los requisitos establecidos en la ley respectiva.

47 Para 2020, la pensión garantizada que otorga el IMSS es de \$3,289.34. La pensión garantizada se actualiza anualmente conforme al Índice Nacional de Precios al Consumidor. Pensión por Régimen 97, México, Conasami, 2020; disponible en bttps://mmn.gob.mx/consar/articulos/ por-regimen-de-97\#: :text=Para\%202020\%20la\%20Pensi\%C3\%B3n\%20Garantizada,necesitas $\% 20$ para\%20realizar $\% 20$ este $\% 20$ retiro\%3F, consultado el 11 de enero de 2021. 
federativas, así como en las disposiciones jurídicas que emanen de todas las anteriores", ${ }^{48}$ equivalentes a 86.88 pesos diarios (4.33 USD) para el 2020 y de 89.62 pesos diarios (4.46 USD) para el 2021; ${ }^{49}$ mientras que el salario mínimo general es de 141.70 pesos diarios (7.06 USD); sin embargo, la Suprema Corte de Justicia de la Nación determinó en el 2019 que no puede aplicarse la cuota diaria para el pago de una pensión con base en UMAS, sino deben ser regidas por el salario mínimo, lo que significa que es una reforma jurídica que contraviene un criterio del Poder Judicial.

\section{B. Diversificación de pensiones}

Antes de la reforma, el artículo 157 de la Ley del Seguro Social (LSS) mencionaba que los asegurados podrían disponer de dos formas de su cuenta individual con el objeto de disfrutar de una pensión de cesantía en edad avanzada, a saber: la renta vitalicia y retiros programados. Previo a la reforma, éstas eran excluyentes una de otra; gracias a la modificación de la ley, ahora se permite que los asegurados elijan una o ambas opciones, siempre y cuando el monto de la renta vitalicia sea mayor al mínimo previsto por el artículo 170 de la misma ley.

\section{Financiación de las pensiones}

Las pensiones se financian de forma tripartita. La reforma no presenta cambios en el porcentaje de cotización de los trabajadores. Por su parte, el artículo 168 de la LSS mantiene que a los empleadores les corresponde cubrir el equivalente del $2 \%$ del salario base de cotización del trabajador para el seguro de retiro, pero modifica las aportaciones en el seguro de cesantía en edad avanzada y vejez, partiendo del actual monto fijo de $3.150 \%$ —el cual se toma como base mínima-, fluctuando hasta el $11.875 \%$. Cabe aclarar que el artículo 2o. transitorio establece que esta modificación será aplicable de manera gradual, a partir del 1o. de enero de 2023 y hasta el 2030, por lo que del 1o. de enero del 2021 al 31 de diciembre del 2022 se mantienen las cuotas fijas que la LSS establecía antes de la reforma, pero sí aumenta ya el monto de la pensión garantizada y sí se disminuyen las semanas de cotización para su obtención.

48 UMA, México, INEGI, 2021; disponible en https://mmw.inegi.org.mx/temas/uma/, consultado el 11 de enero de 2021.

49 Idem. 
De la misma forma se retrasa hasta finales del 2022 la derogación de la fracción tercera que establece las aportaciones que el Estado realiza al seguro de cesantía en edad avanzada y vejez correspondientes al 7.43\% del total de las cuotas patronales, lo que significa que se reducirán las aportaciones estatales y el costo de la reforma la cargarán los empleadores.

La fracción cuarta del artículo 168 hace referencia a las cuotas sociales que son aportaciones hechas por el Gobierno federal a los trabajadores que ganen hasta cuatro veces la unidad de medida y actualización; ésta se depositará en la cuenta individual de cada trabajador, siendo un gran detrimento con relación al mismo artículo previo a la reforma (que cubría hasta 15 veces el salario mínimo).

El tercero transitorio menciona - con relación a esta fracción- que lo dispuesto por este numeral será aplicable a partir del primero de enero del 2023, por lo que, del 1 de enero al 31 de diciembre de 2022, el Gobierno federal cubrirá de igual manera, por concepto de cuota social (dependiendo de una tabla creada para este transitorio), a aquellos trabajadores que ganen entre 4 y 7.09 veces la unidad de medida y actualización.

Por último, no se omite que en los artículos 172, 172 A y 302, además de los transitorios quinto, sexto y séptimo, se menciona que la Secretaría de Hacienda y Crédito Público podrá revisar los procedimientos que el Instituto Mexicano del Seguro Social realice con el fin de verificar la información aportada por él, lo que en teoría aporta un mayor control sobre la institución.

\section{Limite al cobro de comisiones de las Afores}

El 16 de diciembre de $2020^{50}$ se reformó el artículo 37 de la Ley de los Sistemas de Ahorro para el Retiro, y se estableció que las comisiones que cobren las administradoras de fondos para el retiro (Afores), por el manejo y administración de recursos para el retiro de las cuentas individuales de los trabajadores a fin de generar rendimientos, ${ }^{51}$ estarán sujetas a un límite máximo.

50 Decreto por el que se reforman, adicionan y derogan diversas disposiciones de la Ley del Seguro Social y de la Ley de los Sistemas de Ahorro para el Retiro, Diario Oficial de la Federación, México, 2020; disponible en https:/ / www.dof.gob.mx/ nota_detalle.php?codigo $=5607729$ \&fec $h a=16 / 12 / 2020$, consultado el 11 de enero de 2021.

51 Las Afore sólo cobran una comisión, Comisión Nacional del Sistema de Ahorro para el Retiro, México, Gobierno de México, Consar, 2020; disponible en https:/ wmw.gob.mx/consar/articulos/ las-afore-solo-cobran-una-comisiont, consultado el 8 de enero de 2021. 
Esto es, el cobro de comisiones ya no podrá exceder de un límite máximo que establecerá la Junta de Gobierno de la Comisión Nacional del Sistema de Ahorro para el Retiro (Consar), ${ }^{52}$ tomando como referencia el promedio aritmético de los cobros en materia de comisiones en los sistemas de contribución definida de los Estados Unidos de América, Colombia y Chile. ${ }^{53}$

Lo anterior resulta relevante si se toma en cuenta que el cobro de comisiones en México depende del crecimiento de los fondos, en contraste con el cobro que se lleva a cabo en Chile y Colombia, el cual depende del crecimiento del salario y el empleo. ${ }^{54}$

Además, el mercado mexicano se conforma de 10 Afores y cada una realizaba el cobro de comisiones diversas, por lo que la reforma incide directamente en el monto máximo de cobro que realicen, ahora considerando los ajustes a la baja o al alza de las comisiones de Estados Unidos, Colombia y Chile. ${ }^{55}$

\section{Nuevos tribunales laborales}

Desaparecen las Juntas de Conciliación y Arbitraje para dar paso a los nuevos Tribunales Laborales y a la instancia encargada de las conciliaciones. Las principales diferencias entre las primeras y los segundos son:

- Los Tribunales Laborales especializados dependen directamente del Poder Judicial y ya no del Ejecutivo, como se organizaban administrativamente las Juntas de Conciliación y Arbitraje.

- Las juntas fungían de manera tripartita ${ }^{56}$ en los laudos, para resolver los conflictos de trabajo entre obreros y patrones; convirtiéndose ahora en tribunales de trabajo unipersonales con controversias que serán resueltas por un juez.

52 Es el organismo que establece las reglas para que el funcionamiento del Sistema de Ahorro para el Retiro (SAR), Qué hacemos, México, Consar, 2020; disponible en bttps:/ / wmw. gob.mx/consar/que-hacemos, consultado el 11 de enero de 2021.

53 Qué hacemos, México, Consar, 2020; disponible en https://wnn.gob.mx/consar/que-hacemos, consultado el 8 de enero de 2021.

54 Cfr. "Afores que han bajado más su comisión y cómo les afecta la reforma”, El Ceo, México, 2020; disponible en https:// elceo.com/economia/ afores-que-han-bajado-mas-su-comision-y-como-les-afecta-la-refor $\mathrm{ma} /$, consultado el 8 de enero de 2021.

55 Idem.

56 ¿Qué hacemos?, México, Gobierno de México, 2020; disponible en https://mwn.gob.mx/ jfca/ que-hacemos, consultado el 7 de enero de 2021. 
- En lugar de la dictaminación de laudos por las Juntas, se emitirán resoluciones o sentencias definitivas por los Tribunales Laborales (del Tribunal Federal de Conciliación y Arbitraje de los Trabajadores al Servicio del Estado y sus homólogos en las entidades federativas).

El nuevo modelo arrancó a nivel federal el 18 de noviembre del $2020^{57}$ con los Tribunales Laborales especializados dependientes del Poder Judicial en una primera etapa con los estados de Campeche, Chiapas, Durango, Estado de México, San Luis Potosí, Tabasco, Zacatecas e Hidalgo. ${ }^{58}$

\section{Servicio de guarderías para bijos de padres trabajadores}

Un avance significativo hacia la equidad de género en prestaciones de seguridad social se consiguió el 21 de octubre del 2020 con la modificación de los artículos 201 y 205 de la LSS referentes al seguro de guarderías, sustituyendo las palabras "hombre" o "mujer" por "persona trabajadora" 59 para referirse a los derechohabientes de las prestaciones para sus hijos del seguro de guarderías. Cabe aclarar que previo a esta reforma, la citada ley discriminaba a los hombres, ${ }^{60}$ quienes sólo podían acceder a este derecho en el caso de viudez, divorcio o cuando ellos ostentaran la custodia por resolución judicial, ${ }^{61}$ la reforma procura un trato igualitario de las y los trabajadores a ejercer el derecho de guarderías para el cuidado de sus hijos menores de cuatro años.

57 Listos para iniciar la reforma laboral, demostraremos a la ciudadanía que el cambio va en serio: Luisa Alcalde, México, Gobierno de México, Secretaría del Trabajo y Previsión Social, 2020; disponible en https:// wmm.gob.mx/stps/prensa/ listos-para-iniciar-la-reforma-laboral-demostrare mos-a-la-ciudadania-que-el-cambio-va-en-serio-luisa-alcalde, consultado el 7 de enero de 2021.

58 Arranca la segunda etapa de implementación de la Reforma Laboral, México, Gobierno de México, Secretaría del Trabajo y Previsión Social, 2020; disponible en https://wnm.gob.mx/stps/pren sa/ arranca-la-segunda-etapa-de-implementacion-de-la-reforma-laboral, consultado el 7 de enero de 2021.

59 Decreto por el que se reforman los artículos 201, primer párrafo y 205, primer párrafo de la Ley del Seguro Social, Diario Oficial de la Federación.

60 Iniciativa con proyecto de decreto que reforma los artículos 201 y 205 de la Ley del Seguro Social; disponible en http://sil.gobernacion.gob.mx/Arcbivos/Documentos/2019/02/asun_3 809565_20190207_1549476168.pdf, consultado el 12 de enero de 2021.

61 Ruiz Ramírez, José Manuel, Acceso a las guarderías y género, México, Suprema Corte de Justicia de la Nación; disponible en bttps:// wmw.scjn.gob.mx/sites/default/files/derechos_humanos/ articulosdh/documentos/2016-12/ ACCESO\%20A\%20LAS\%20GUARDER\%C3\%8DAS.pdf, consultado el 12 de enero de 2021. 
5. Protección de riesgos psicosociales para los trabajadores en México

El 23 de octubre de 2019 entró en vigor la Norma Oficial Mexicana NOM035-STPS-2018 relativa a la prevención de riesgos psicosociales en el trabajo.

La primera etapa concluyó el 23 de octubre del 2020, e inició la segunda etapa en la cual los centros de trabajo, cuyas evaluaciones previamente determinen la necesidad de desarrollar acciones de control, deben implementar a través de un programa la atención de los factores de riesgo psicosocial, que propicie un entorno organizacional favorable y prevenir actos de violencia laboral. ${ }^{62}$

Dicho programa debe contener las áreas de trabajo y/o trabajadores sujetos, tipo de acciones y medidas de control, fechas para su realización, control de avances de la implementación y la evaluación posterior; esta disposición aplica a centros de trabajo con más de 15 trabajadores. ${ }^{63}$

Las evidencias impresas o en medios electrónicos se conservarán por lo menos un año, desde la fecha de elaboración, y podrán ser por constatación, revisión documental, registros o entrevistas, que se presentarán al momento de la visita de inspección o verificación (según corresponda) por la autoridad laboral. ${ }^{64}$

\section{Vivienda}

Una prestación poco común para los seguros sociales es la de vivienda, a la que tienen derecho los trabajadores de la iniciativa privada asegurados en el IMSS a través del Infonavit y para los servidores públicos federales a través del ISSSTE, y en este año se presentaron las siguientes reformas:

1a. Creación del programa ConstruYo. Es un programa que empezó a operar el 31 de agosto de 2020 manejado por el Infonavit en los estados de Baja California, Chiapas, Jalisco, Nayarit, Oaxaca, Yucatán y Zona Metropolitana del Valle de México ${ }^{65} \mathrm{y}$, dependiendo las necesidades del

62 Norma Oficial Mexicana NOM-035-STPS-2018, Factores de riesgo psicosocial en el trabajo. Identificación, análisis y prevención, Diario Oficial de la Federación, México, 23 de octubre de 2018; disponible en https://wmw.dof.gob.mx/nota_detalle.php?codigo $=5541828$ \& fec $b a=23 / 10 / 2018$, consultado el 7 de enero de 2021 .

63 Idem.

64 Idem.

65 ConstruYO, Infonavit, México, 2020; disponible en https://portalmx.infonavit.org.mx/wps/ portal/infonavit.web/trabajadores/construYO/!ut/p/₹1/jZBND4IwDIZ_DVfaicHpDQkOP2LUuI 
trabajador, se otorga en tres supuestos: para reparaciones menores de la vivienda propiedad del trabajador, para la autoconstrucción o remodelación de una vivienda, y para la construcción o remodelación de vivienda mediante la empresa constructora de elección del trabajador (cabe aclarar que en los primeros dos supuestos se contará con una verificación, y en el último es responsable directamente la compañía constructora frente al Infonavit).

2a. El 16 de diciembre de 2020 se reforman la Ley del Infonavit ${ }^{66}$ y la Ley del ISSSTE, ${ }^{67}$ y se incluye como una de las prestaciones de ambos institutos el otorgar créditos al trabajador para la adquisición en propiedad del suelo destinado para la construcción de sus habitaciones ${ }^{68}$

3a. Las aportaciones de los trabajadores asegurados del IMSS se depositan en una cuenta individual, administrada por una Afore. Esta cuenta se divide a su vez en tres subcuentas y una de ellas acumula los recursos para el seguro de vivienda. Al respecto, el artículo 37 de la Ley del Infonavit mencionaba que el derecho de disponer de los recursos de esta subcuenta (por el trabajador o sus beneficiarios) prescribía a favor del Infonavit transcurrido el plazo de 10 años, ${ }^{69}$ una vez que fuera exigible este derecho. Con la reforma al citado artículo se crea un procedimiento por el cual Infonavit podrá disponer de los montos de las subcuentas, además señala que un año antes de que se cumpla el plazo señalado (10 años), el Infonavit hará del conocimiento del trabajador o beneficiarios el tiempo que ha transcurrido para exigir este derecho; la notificación se dejará a la facultad discrecional del mismo instituto. Transcurrido el plazo ya mencionado, el Infonavit podrá constituir una reserva financiera con esos recursos.

C7GDA4SIAZmPL3RT2ZCNJbmdp8xYEhCDK6JHJSGegjPK2Pwn7bDNE3×2TLTu4Fu53R vlfI_ryQSCNzCiiGyOLUB9is7CW3rTjTV inIAY4mNHOTjM7wFE_oAxBvpSkDwD_CKO_ ICoTMVf25p1PGFpUgquSaVEll3qt2nGp9q2cGGtg0jSmV knliX/Rh4C8lVbWG8JuEW8F5iN muCGj9BCcSOvg!/dz/d5/L2dBISEvZOFBIS9nQSEh/, consultado el 12 de enero de 2021.

66 Se modifican los artículos 41, párrafo primero; 42, fracción II, incisos a), b), c) y d); 43 Bis, párrafo tercero; 47, párrafos segundo, cuarto y quinto; 48; 49, párrafos primero y segundo, y, 50; y se adicionan al artículo 3o., fracción II, inciso d); 42, fracción II, inciso e), y un segundo párrafo.

67 Se reformaron los artículos 167, párrafo tercero; 176, párrafo tercero; 179, párrafo primero y 181; y se adicionan a los artículos 169, fracción I, inciso d); y 178, un párrafo segundo, de la Ley del Instituto de Seguridad y Servicios Sociales de los Trabajadores del Estado.

68 Se entiende por suelo el terreno sobre el cual el trabajador pretende construir.

69 Decreto por el que se reforma el artículo 37 de la Ley del Instituto del Fondo Nacional de la Vivienda para los Trabajadores, Diario Oficial de la Federación, 16 de diciembre de 2020. 
Cabe aclarar que se protege el derecho de los trabajadores, quienes podrán exigir los montos de la subcuenta de vivienda por medio de un mecanismo de reclamación ante el instituto (el cual no ha sido definido), aún transcurridos los 10 años.

\section{Cambios en las cuestiones de financiamiento}

De forma general, destaca el aumento del presupuesto en materia de seguridad social, que en 2019 se estableció para el ejercicio 2020 en $\$ 863611$ 766125.00 (ochocientos sesenta y tres mil seiscientos once millones setecientos sesenta y seis mil ciento veinticinco pesos 00/100 M.N. ${ }^{70}$ (43,051 billón USD), y para el ejercicio 2021 se aumentó a $\$ 961,026,461,285.00$ (Novecientos sesenta y un mil veintiséis millones cuatrocientos sesenta y un mil dos cientos ochenta y cinco pesos 00/100 M.N.) ${ }^{71}$ (47,907 billón USD).

También resaltan los montos asignados por primera vez en el presupuesto anual, para dar cumplimiento a prestaciones en materia de seguridad social y de servicios de salud que se mencionan a continuación.

\section{A. Incorporación de presupuesto para la seguridad social de los productores de caña de azúcar}

Dentro del Presupuesto de Egresos de la Federación para el Ejercicio Fiscal $2020^{72}$ se incorporó un monto de 280 millones de pesos, (14 millones USD) para dar cumplimiento a la incorporación por decreto presidencial ${ }^{73} \mathrm{al}$ régimen del seguro social obligatorio otorgado por el IMSS a los productores de caña, que les otorga las prestaciones de los siguientes seguros: Riesgos de Trabajo, Enfermedades y Maternidad, Invalidez y Vida, Retiro, Cesantía en Edad Avanzada y Vejez y Guarderías y Prestaciones Sociales.

70 Presupuesto de Egresos de la Federación para el Ejercicio Fiscal 2020, Diario Oficial de la Federación, México, Cámara de Diputados del H. Congreso de la Unión, 2020; disponible en http://mww.diputados.gob.mx/LeyesBiblio/abro/pef_2020/PEF_2020_abro.pdf, consultado el 7 de enero de 2021.

71 Presupuesto de Egresos de la Federación para el Ejercicio Fiscal 2021, Diario Oficial de la Federación, México, Cámara de Diputados del H. Congreso de la Unión; disponible en http:/ / wnw.diputados.gob.mx/LeyesBiblio/pdf/PEF_2021_301120.pdf, consultado el 7 de enero de 2021.

72 Presupuesto de Egresos de la Federación para el Ejercicio Fiscal 2020..., cit.

73 Artículos 236 y 12 fracción III de la Ley del Seguro Social. 
B. Incorporación de subsidio para el financiamiento de las prestaciones por licencia para padres de hijos con cáncer

El 4 de junio de 2019 entró en vigor el "Decreto por el que se adicionan diversas disposiciones de la Ley del Seguro Social, de la Ley del Instituto de Seguridad y Servicios Sociales de los Trabajadores del Estado y de la Ley Federal del Trabajo", ${ }^{74}$ con el cual las madres o padres trabajadores asegurados podrán ausentarse de sus labores para el cuidado de sus hijos diagnosticados con cáncer, y gozarán de una licencia por cuidados médicos equivalente al $60 \%$ del último salario diario de cotización registrado por el empleador, durante un periodo máximo de 364 días en 3 años, en licencias de 1 a 28 días. ${ }^{75}$

Por lo que se incluye en el Presupuesto de Egresos de la Federación para el Ejercicio Fiscal $2020^{76}$ un monto de 498.8 millones de pesos (24,865 millones USD), sólo para el IMSS; además, por el mismo concepto, se designó un presupuesto de 168 millones de pesos para ser ejercidos por el ISSSTE. Lo anterior destinado para cubrir los gastos originados por dicha prestación económica.

\section{SEGURIDAD SOCIAL INTERNACIONAL}

En este apartado se reportan los dos acontecimientos siguientes.

\section{El nuevo Tratado de Libre Comercio entre México, Estados Unidos de América y Canadá}

El primero de julio de 2020 entró en vigor el nuevo tratado de libre comercio denominado "Tratado entre México, Estados Unidos y Canadá" (T-MEC/ USMCA) que sustituye al North American Free Trade Agreement (NAFTA), y que

74 Decreto por el que se adicionan diversas disposiciones de la Ley del Seguro Social, de la Ley del Instituto de Seguridad y Servicios Sociales de los Trabajadores del Estado y de la Ley Federal del Trabajo, Diario Oficial de la Federación, México; disponible en bttps: / dof.gob.mx/ nota_detalle.php?codigo $=5561817$ erfecha $=04 / 06 / 2019$, consultado el 7 de enero de 2021 .

75 Artículo 140 bis de la LSS.

76 Inventario Coneval de Programas y Acciones Federales de Desarrollo Social 2019-2020. Presentación y Análisis, México, Coneval, 2020, p. 35; disponible en https://mnw.coneval.org.mx/evaluacion/ipfe/ Paginas/default.aspx, consultado el 7 de enero de 2021. 
permite atender las nuevas necesidades y realidades en materia comercial entre los países intervinientes.

De manera particular destacan en derecho social algunas novedades del T-MEC:

1) El T-MEC se distingue por estar compuesto por 34 capítulos $^{77}$ y sus aspectos trascendentales en materia laboral se encuentran contenidos en el capítulo 23 del tratado en el que las partes se comprometen, esencialmente, a adoptar e implementar en sus legislaciones los derechos establecidos a Declaración de la OIT relativa a los principios y derechos fundamentales en el trabajo, de 1998, que incluye entre otros temas la eliminación de todas las formas de trabajo forzoso u obligatorio, incluido el trabajo infantil; inclusive, la prohibición de importar mercancías producidas bajo estas condiciones. ${ }^{78}$

2) Si bien en el NAFTA se establecían prohibiciones de discriminación respecto de los proveedores ${ }^{79} \mathrm{o}$ en materia de licitación, ${ }^{80}$ en el T-MEC se incorporan además compromisos específicos para proteger a los trabajadores de la discriminación de género, pues se reconoce el objetivo de eliminar la discriminación tanto en el empleo y la ocupación, y apoyar el objetivo de promover la igualdad de la mujer en el centro de trabajo, protegiéndolas de cualquier discriminación de género, incluido el acoso sexual, embarazo, orientación sexual, identidad, etc. ${ }^{81}$

3) Por otra parte, el T-MEC aborda la protección de los trabajadores migrantes, señalando que deberán estar protegidos conforme a las leyes laborales de los países, sean o no nacionales, ${ }^{82}$ para así establecer mecanismos de protección en defensa de sus derechos: No obstante, lo anterior no incluye medidas en pro de la circulación de trabajadores.

77 Tratado entre los Estados Unidos Mexicanos, los Estados Unidos de América y Canadá, México, Gobierno Mexicano, 2020; disponible en bttps:/ / wnw.gob.mx/t-mec/acciones-y-programas/ textos-finales-del-tratado-entre-mexico-estados-unidos-y-canada-t-mec-202730? state= published, consultado el 25 de enero de 2021.

78 Ibidem, capítulo 23, artículo 23.6.

79 Ibidem, artículo 1003.

80 Ibidem, artículo 1008.

81 Ibidem, capítulo 23, artículo 23.9.

82 Ibidem, capítulo 23, artículo 23.8. 


\section{El registro del Convenio sobre las Trabajadoras y los Trabajadores Domésticos,} 2011 (núm. 189) ante la Organización Internacional del Trabajo

El 3 de julio de 2020 se llevó a cabo el registro del Convenio sobre las Trabajadoras y los Trabajadores Domésticos, 2011 (núm. 189) ante el director general de la Organización Internacional del Trabajo (OIT) ${ }^{83}$ El decreto respectivo se publicó anteriormente el 20 de enero de 2020 en el Diario Oficial de la Federación. El registro formal del Convenio 189 da inicio a la cuenta regresiva para su entrada en vigor, el cual, en un plazo de doce meses, tendrá rango constitucional. ${ }^{84} \mathrm{El}$ artículo 14 de dicho convenio establece que las y los trabajadores domésticos deben disfrutar de condiciones no menos favorables que las condiciones aplicables a los trabajadores en general con respecto a la protección de la seguridad social, inclusive en lo relativo a la maternidad, por lo que seguramente tendremos reformas en la Ley Federal del Trabajo en este año $2021 . .^{85}$

\section{CONCLUSIONES}

Como se ha podido constatar en este informe, la seguridad social de México, pese a la pandemia, ha dado un avance importante en materia jurisdiccional, pues esto es reconocible a través de las diversas resoluciones que sin aplicación stricto sensu de la norma, han podido ampliar su cobertura; por ejemplo, con los extranjeros, al reclamar sus ahorros acumulados en las cuentas individuales y la protección que se debe dar a los trabajadores en la pandemia.

En el aspecto legislativo, resulta sumamente interesante la reforma a las pensiones de 2020, en función de que al no contar con una clara planeación financiera, no se puede sostener que sea una reforma acertada. Seguramente cuenta con una buena intención, y por lo mismo con una excelente aceptación de los beneficiarios de dicha reforma, pero esto no garantiza su sustentabilidad.

83 México y el Convenio 189 de la OIT, 2020; disponible en https:/ / wnm.onu.org.mx/ wp-content/ uploads /2020/07/M\%C3\%A9xico-y-el-Convenio-189-de-la-OIT.pdf, consultado el 7 de enero de 2021.

84 Cfr. "México salda su deuda histórica con los 2,3 millones de trabajadoras domésticas al ratificar el 'Convenio 189”, Noticias ONU, 2020; disponible en bttps:// news.un.org/es/story/2020/07/1477151, consultado el 7 de enero de 2021.

85 C189 Convenio sobre las trabajadoras y los trabajadores domésticos, OIT, 2011 (núm. 189), artículo 14; disponible en https:// www.ilo.org/dyn/ normlex/es/f?p=NORMLEXPUB:12100:0:: NO::P12100_ILO_CODE:C189, consultado el 12 de enero de 2021. 
Por último, en materia internacional, se reconoce un avance significativo ya presentado desde el año anterior en la protección de las y los trabajadores domésticos. Lamentablemente el nuevo T-MEC no incluye normas específicas de seguridad social, y seguramente los mexicanos deberemos esperar veinte años más para ver iniciar una verdadera negociación que nos lleve a una integración regional. Porque éste inicia efectivamente por una integración económica con la libertad de mercancías, pero a ella debiera seguir la libre circulación de trabajadores, y posteriormente de todas las personas; en los dos últimos casos es indispensable el cobijo de la seguridad social desde el principio.

\section{FUENTES DE INVESTIGACIÓN}

"Acuerda Conasami incremento del salario mínimo del 15\% para 2021", México, Gobierno de México, Comisión Nacional de Salarios Mínimos, 2020; disponible en https://wmm.gob.mx/conasami/prensa/acuerda-conasamiincremento-del-salario-minimo-del-15-para-2021-259690.

Acuerdo ACDO.AS2.HCT.240620/173.P.DPES, dictado por el H. Consejo Técnico en sesión ordinaria de 24 de junio de 2020, por el que se autorizan estrategias para prorrogar las prestaciones en especie y/o en dinero a los asegurados con incapacidad temporal para el trabajo que lleguen a término de ley y a los beneficiarios hijos incapacitados que cumplen 16 años, así como reconocimiento de la enfermedad COVID-19 como riesgo de trabajo en trabajadores IMSS, durante el periodo de contingencia, Diario Oficial de la Federación, México, Secretaría de Gobernación, 2020; disponible en https:// www.dof.gob.mx/nota_detalle.php?codigo $=5597452$ orfecha $=29 / 07 / 2020$.

Acuerdo por el que se declara como emergencia sanitaria por causa de fuerza mayor, a la epidemia de enfermedad generada por el virus SARS-CoV-2 (COVID-19), Diario Oficial de la Federación, México, 2020; disponible en bttps:/ / www.dof.gob.mx/nota_detalle.php?codigo $=5590745 \& f e c h a=30 / 03 / 2020 \#: \sim$ :te $x t=$ Primero. - ,Se $\% 20$ declara $\% 20$ como\%20emergencia\%20sanitaria\%20por $\% 20$ cau sa $\% 20$ de $\% 20$ fuerza $\% 20$ mayor,prevista $\% 20$ en $\% 20$ el $\% 20$ numeral $\% 20$ anterior.

Acuerdo por el que se emiten las Reglas de Operación del Programa de Salud y Bienestar Comunitario, para el Ejercicio Fiscal 2020, Diario Oficial de la Federación, México; disponible en https:/ / www.dof.gob.mx/nota_detalle.php?codi $g_{0}=5583027$ Erfech $a=28 / 12 / 2019$. 
Acuerdo por el que se emiten los Lineamientos de Operación del Programa para el Bienestar de las Personas en Emergencia Social o Natural para el Ejercicio Fiscal 2020, Diario Oficial de la Federación, México, 2020; disponible en https:// wmw.gob.mx/cms/uploads/attachment/file/578546/Lineamientos_Emergencia_Social.pdf.

Adultos mayores recibirán bimestre adelantado de pensión, anuncia presidente; programas sociales se fortalecerán ante COVID-19, México, Gobierno de México, 2020; disponible en https://presidente.gob.mx/adultos-mayores-reci biran-bimestre-adelantado-de-pension-anuncia-presidente-programas-sociales-se-fortaleceran-ante-covid-19/.

"Afores que han bajado más su comisión y cómo les afecta la reforma", El Ceo, México, 2020; disponible en https:// elceo.com/economia/afores-que-hanbajado-mas-su-comision-y-como-les-afecta-la-reforma/.

Arranca la segunda etapa de implementación de la Reforma Laboral, México, Gobierno de México, 2020; disponible en bttps://wmm.gob.mx/stps/prensa/arrancala-segunda-etapa-de-implementacion-de-la-reforma-laboral.

BBVA México: En 2020, las remesas alcanzarán los 39,500 millones de dólares pese a la pandemia, México, BBVA, 2020; disponible en https://mmw.bbva.com/ es/mx/ bbva-mexico-estima-que-en-2020-las-remesas-alcanzaran-los-39500-mdd8-4-pese-a-la-pandemial.

Becas para el Bienestar Benito Juárez, Conferencias sobre Programas del Bienestar, México, Gobierno de México, Secretaría de Trabajo y Previsión Social, 2020; disponible en https://mmw.gob.mx/stps/articulos/becas-para-el-bienestar-benitojuarez-conferencias-bienestar.

C189-Convenio sobre las trabajadoras y los trabajadores domésticos, OIT, 2011 (núm. 189), Artículo 14; disponible en bttps:// wmw.ilo.org/dyn/normlex/es $/ f$ ? $p=N$ ORMLEXPUB:12100:0::NO::P12100_ILO_CODE:C189.

Cambios estructurales en el mercado laboral, Banco de México, 2020; disponible en https:// wmw.banxico.org.mx/publicaciones-y-prensa/presentaciones/\%7B03A31A C2-D1CD-COCA-955B-B8AEFE71AFAB\%7D.pdf.

COMISIÓN ECONÓMICA PARA AMÉRICA LATINA Y EL CARIBE, Enfrentar los efectos cada vez mayores del COV ID-19 para una reactivación con igualdad: nuevas proyecciones, 2020, p. 5; disponible en https:// repositorio.cepal.org/bitstream/ handle /11362/45782/4/S2000471_es.pdf.

ConstruYO, México, Infonavit, 2020, disponible en https://portalmx.infonavit.org. $m x / w p s /$ portal/ infonavit.web/trabajadores/construYO/!ut/p/ z.1/ jZBND4IwDIZ_DVfaicHpDQkOP2LUuIC7GDA4SIAZmPL3RT2ZC 
NJbmdp8xYEhCDK6JHJSGeqjPK2Pwn7bDNE3×2TLTu4Fu53RचJl fI_ryQSCNzCiiGyOLUB9is7CW3rTjTVinIAY4mNHOTjM7wFE_oA xBvpSkDwD_CKO_ICoTMVfz5p1PGFpUgquSaVEll3qt2nGp9q2cGGtg0j SmVknliX/Rb4C8lVbWG8JuEW8F5iNmuCGj9BCcS0vg!/dz/d5/L2dBI SEvZOFBIS9nQSEh/.

Convenio con hospitales privados iTodos juntos contra el COVID-19!, México, 2020; disponible en https://mmm.gob.mx/issste/es/articulos/convenio-con-hospitales-pri vados?idiom $=e$.

COVID-19 México, México, Gobierno de México, 2021; disponible en https:/ / datos.covid-19.conacyt.mx/; consultado el 7 de enero de 2021.

Decreto por el que se adicionan diversas disposiciones de la Ley del Seguro Social, de la Ley del Instituto de Seguridad y Servicios Sociales de los Trabajadores del Estado y de la Ley Federal del Trabajo, Diario Oficial de la Federación, México; disponible en https: / / dof.gob.mx/nota_detalle.php?codigo $=5$ 561817 éfecha $=04 / 06 / 2019$.

Decreto por el que se reforman, adicionan y derogan diversas disposiciones de la Ley del Seguro Social y de la Ley de los Sistemas de Ahorro para el Retiro, Diario Oficial de la Federación, México, 2020; disponible en bttps:// wnw.dof.gob.mx/nota_detalle.php?codigo $=5607729$ orfecha $=16 / 12 / 2020$.

Evolución de las lineas de pobreza por ingresos, México, Coneval, 2020; disponible en https:// mmw.coneval.org.mx/Medicion/MP/Paginas/Lineas-de-bienestar-ycanasta-basica.aspx.

Guia para implementar el teletrabajo en los centros de trabajo en el marco de las acciones para enfrentar el COVID-19, Secretaría del Trabajo y Previsión Social, México, 2020; disponible en https://wwm.gob.mx/cms/uploads/attachment/ file/543661/INTRODUCCIO_N.pdf.

Informes de perspectivas de la economía mundial octubre de 2020, Fondo Monetario Internacional, Estados Unidos de América, 2020; disponible en bttps:// www.imf.org/es/Publications/WEO/Issues/2020/09/30/world-economic-out look-october-2020.

Informe sobre el comercio y el desarrollo 2020 de la pandemia mundial a la prosperidad para todos: evitar otra década perdida, Organización de las Naciones Unidas, Suiza, 2020; disponible en https://wmw.onu.org.mx/presentacion-del-informe2020-sobre-comercio-y-desarrollo-de-la-unctad/.

Informe sobre las Migraciones en el Mundo 2020, Suiza, OIM-ONU, 2020; disponible en https://publications.iom.int/system/files/pdf/wmr_2020_es.pdf. 
Inventario Coneval de Programas y Acciones Federales de Desarrollo Social 2019-2020. Presentación y Análisis, México, Coneval, 2020; disponible en https:// wmw. coneval.org. $m x$ / evaluacion/itfe/Paginas/default.aspx.

Las Afore solo cobran una comisión, Comisión Nacional del Sistema de Ahorro para el Retiro, México, Gobierno de México, 2020; disponible en https:// wnw.gob.mx/consar/articulos/las-afore-solo-cobran-una-comisiont.

Listos para iniciar la reforma laboral, demostraremos a la ciudadania que el cambio va en serio: Luisa Alcalde, Gobierno de México, Secretaría del Trabajo y Previsión Social, México, 2020; disponible en https://wnm.gob.mx/stps/prensal listos-para-iniciar-la-reforma-laboral-demostraremos-a-la-ciudadania-que-el-cambiova-en-serio-luisa-alcalde.

LXIV/3PPO-72, Gaceta del Senado, México, Senado de la República, 2020, miércoles 9 de diciembre de 2020, disponible en https://mmm.senado.gob. $m x / 64 / g a c e t a \_d e l \_s e n a d o / 2020 \_12 \_09 / 2757 \# 418$.

Medición de la pobreza, México, Coneval, 2020; disponible en https:// wmm. coneval.org.mx/Medicion/Paginas/PobrezaInicio.aspx; consultado el 5 de enero de 2021.

México salda su deuda bistórica con los 2,3 millones de trabajadoras domésticas al ratificar el "Convenio 189", Noticias ONU, 2020; disponible en https:// news.un.org/ es/story/2020/07/1477151.

México y el Convenio 189 de la OIT, 2020; disponible en bttps:/ / wmw.onu.org.mx / wp-content/ uploads/2020/07/M\%C3\%A9xico-y-el-Convenio-189-de-la-OIT.pdf.

Norma Oficial Mexicana NOM-035-STPS-2018, Factores de riesgo psicosocial en el trabajo- Identificación, análisis y prevención, Diario Oficial de la Federación, 23 de octubre de 2018, México; disponible en bttps:// wmw.dof. gob.mx $/$ nota_detalle.php? codigo $=5541828$ erfecha $=23 / 10 / 2018$.

Pensión por Régimen 97, México, Consar, 2020; disponible en https://wmw. gob.mx/consar/articulos/por-regimen-de-97\#: :text=Para\%202020\%20la\%20 Pensi\%C3\%B3n\%20Garantizada,necesitas\%20para\%20realizar\%20este\%2 Oretiro\%3F.

Personas que perdieron su empleo durante emergencia sanitaria pueden tramitar retiro parcial por desempleo: IMSS, México, IMSS, 2020; disponible en http:// wmm. imss.gob.mx/prensa/archivo/202006/368.

Presupuesto de Egresos de la Federación para el Ejercicio Fiscal 2020, Diario Oficial de la Federación, México; disponible en http:/ / wmw.diputados.gob.mx/ LeyesBiblio/abro/pef_2020/PEF_2020_abro.pdf. 
Presupuesto de Egresos de la Federación para el Ejercicio Fiscal 2021, Diario Oficial de la Federación, México; disponible en http:/ / wmw.diputados.gob.mx/ LeyesBiblio/pdf/PEF_2021_301120.pdf.

Programa $3 \times 1$ para Migrantes, México, Secretaría de Desarrollo Social; disponible en bttp:// www.sedesol.gob.mx/work/models/SEDESOL/Transparencia/ TransparenciaFocalizada/Programas_Sociales/pdf/3x1_para_migrantes.pdf.

Programa de Coinversión Social, México, Secretaría de Desarrollo Social; disponible en http://www.sedesol.gob.mx/work/models/SEDESOL/Transparencia/ TransparenciaFocalizada/Programas_Sociales/pdf/coinversion_social.pdf.

Qué hacemos, México, Consar, 2020; disponible en https://mmm.gob.mx/consar/que-hacemos.

¿Qué hacemos?, México, Gobierno de México, 2020; disponible en https: / wmw. gob.mx/jfca/ que-hacemos.

¿Quiénes somos?, México, Coneval, 2020; disponible en https:// wmw.coneval.org. $m x /$ quienessomos/Paginas/Quienes-Somos.aspx.

Resultados de la encuesta nacional de ocupación y empleo. nueva edición (ENOEN) cifras durante el tercer trimestre de 2020, México, INEGI, 2020; disponible en https:// www.inegi.org.mx/contenidos/programas/enoe/15ymas/doc/enoe_n_nota_tecnica_trim 3.pdf.

Ruiz Ramírez, José Manuel, Acceso a las guarderías y género, México, Suprema Corte de Justicia de la Nación; disponible en https://mmm.scjn.gob.mx/ sites/default/files/derechos_humanos/articulosdh/documentos/2016-12/ACCE SO\%20A\%20LAS\%20GUARDER\%C3\%8DAS.pdf.

Segundo Informe de Gobierno 2020, México, Gobierno de México, Presidencia de la República, 2020; disponible en https://presidente.gob.mx/wp-con tent/uploads/2020/09/PRESIDENTE\%20AMLO\%202INFORME\%20 DE\%20GOBIERNO\%202019-2020.pdf.

Tipo de cambio, México, Banco de México, 2021; disponible en https://wmw. banxico.org. $m x /$ tipcamb/main.do?page= tipe \&idioma $=$ sp.

Tratado entre los Estados Unidos Mexicanos, los Estados Unidos de América y Canadá, México, Gobierno de México, 2020; disponible en https://mmw.gob.mx/tmec/acciones-y-programas/textos-finales-del-tratado-entre-mexico-estados-unidos-ycanada-t-mec-202730? state $=$ published.

UMA, México, INEGI, 2021; disponible en https://wmw.inegi.org.mx/temas/ umal. 
Votaciones del primer periodo ordinario del tercer año de la LXIV Legislatura, Servicio de la Gaceta Parlamentaria, México, Cámara de Diputados, 2020; disponible en http://gaceta.diputados.gob.mx/Gaceta/ Votaciones/64 / vot 64_a3primero.html. 